\title{
Application of basalt-FRP bars for reinforcing geotechnical concrete structures
}

\author{
Marta Kosior-Kazberuk ${ }^{1, *}$ \\ ${ }^{1}$ Bialystok University of Technology, 45E Wiejska St., Bialystok, 15-351, Poland
}

\begin{abstract}
The fiber reinforced polymer (FRP) bars have become a useful substitute for conventional reinforcement in civil engineering structures for which load capacity and resistance to environmental influences are required. They are often used in concrete structural elements exposed to strong environmental aggression, such as foundations, breakwaters and other seaside structures, road structures and tanks. The basalt fiber-reinforced polymer (BFRP) is the most recently FRP composite, appearing within the last decade. Due to their mechanical properties different from steel bars, such as higher tensile strength and lower Young's modulus, BFRP bars are predestined for use in structures for which the ultimate limit state is rather decisive than serviceability limit state. Experimental tests were carried out to assess the influence of static long-term loads and cyclic freezing/thawing on the behaviour of concrete model beams with non-metallic reinforcement. The bars made of basalt fiber reinforced polymer (BFRP) and hybrid (basalt and carbon) fiber reinforced polymer (HFRP) were used as non-metallic reinforcement. The mechanical properties of both types of bars were also determined.
\end{abstract}

\section{Introduction}

The composite bars have become a useful substitute for conventionalreinforcement in civil engineering structuresfor which load capacity and resistance to environmental influences are required [3-7]. Fibre Reinforced Polymer (FRP) has been widely used for reinforcement or rehabilitation of the upper structures. Currently, some research has investigated the application of FRP in underground structures, mainly the reinforcement of the structures or substitution of traditional material $[10,14]$.

The FRP composite products are mostly manufactured into FRP sheets and FRP bars for different construction purposes. FRP bars usually include GFRP anchor (ribs), GFRP grille [26] and FRP piles [18]. A notable method utilizing the confinement to concrete columns by FRP has been studied in $[13,25]$. There is a large amount of research focus on the analyzing the structural behavior of beams and walls with consideration of FRP sheet $[15,16]$ and bars application $[6,7,22]$. The composite bars are often used in concrete structural elements exposed to strong environmental aggression, such as foundations, breakwaters and other seaside structures, road structures and tanks and other geotechnical structures in sewage treatment plants $[9,10,14]$.

*Corresponding author: m.kosior@pb.edu.pl 
FRP is characterized by high ratio of strength to weight, high ratio of longitudinal/transversal Young modulus and high ratio of longitudinal/transversal shear modulus. Depending on the material of fibers there are aramid-FRP (AFRP), carbon-FRP (CFRP), glass-FRP (GFRP) and basalt-FRP (BFRP). The FRP products are flexible to change the material properties through designing volume ratio of fibers to resin and selecting the types and orientation of fiber. The composite bars are susceptible to varying amounts of strength and stiffness changes in the presence of environments before, during, and after construction. These environments can include water, ultraviolet exposure, elevated temperature, alkaline or acidic solutions. FRP bars are corrosion resistant; therefore, the maximum crack width limitation can be relaxed when corrosion of reinforcement is the primary reason for crack width limitations. Other considerations with regard to acceptable crack width limit include aesthetics and shear effect. Tensile and bond properties of FRP bars are the primary parameters of interest for reinforced concrete structures [17, 21-24].

In spite of dissemination of different types of non-metallic bars and numerous investigations of structural members reinforced using these bars, this type of reinforcement is still treated as an unconventional construction material. One of the barrier of non-metallic bars application is the lack of standards and clear guidelines for the design of concrete structures reinforced with FRP bars. No standards have been developed for determining the mechanical parameters of FRP reinforcing bars, and thus the separate mechanical properties tests should be carried out foreach application of this type of reinforcement. In order to improve the properties of composite reinforcement for concrete structures, the attempts are made to manufacture hybrid bars containing different fibers [20, 23].

The relatively least amount of research concerns the use of basalt fiber reinforced polymer (BFRP) bars. In addition to the excellent corrosion resistance and mechanical characteristics, the basalt fiber is environmentally harmless and has a good range of thermal performance, superior electro-magnetic property, and good resistance to impact, which makes it better than the glass fiber and less expensive than carbon fiber [11, 19, 21]. Even fewer studies concern the use of hybrid fiber reinforced polymer (HFRP) bars in which, besides basalt fibers, also carbon fibers have been introduced to increase the modulus of elasticity [20].

The paper concerns the application of basalt (BFRP) bars and hybrid (HFRP) bars as reinforcement for concrete structures with improved durability. The aim of the research was to assess the behavior of model beams made of concrete reinforced with BFRP and HFRP bars, subjected to interaction of static load in three-point bending test and cyclic freezing-and thawing. The effect of strengthening basalt barsusing carbon fibers on mechanical parameters was considered.

\section{Properties of composite reinforcing bars tested}

The composite basalt (BFRP) bars and hybrid (HFRP) bars wereused as the reinforcementof model beams. Both of them were produced by the same manufacturer. The first type is based on rovings made with basalt fibers, the other is based on rovings with basalt and carbon fibers. All bars were made using pultrusion method with appropriate fibers immersed in a polyester matrix. The material was formed into smooth bars wrapped with an additional braid increasing their adhesion to concrete.

The results of strength tests of reinforcing bars carried out in accordance with the guidelines ACI 440.3R-04 [2] were shown in Table 1. The applied standard concerns mainly reinforcementof carbon, glass and aramid bars. However, the guidelines for the reinforcement of basalt fiber bars have not been developed yet. The following properties were determined:

- $\mathrm{f}_{\mathrm{fu}}^{*}$ - guaranteed tensile strength, defined as the mean tensile strength $\mathrm{f}_{\mathrm{u} \text {,ave }}$ minus three times standard deviation $\sigma_{\mathrm{s}}$, 
- $\mathrm{E}_{\mathrm{f}}$ - design or guaranteed modulus of elasticity of FRP defined as mean modulus of test specimens $\left(\mathrm{E}_{\mathrm{f}}=\mathrm{E}_{\mathrm{f}, \mathrm{ave}}\right)$,

$-\varepsilon_{\mathrm{fu}}^{*}$ - guaranteed rupture strain of FRP reinforcement defined as the mean tensile strain at failure of test specimens minus three times standard deviation $\sigma$.

Table 1. Basic strength parameters of BFRP and HFRP bars.

\begin{tabular}{|c|c|c|c|c|c|c|c|}
\hline Bar type & $\mathrm{f}_{\mathrm{u}, \mathrm{ave}}$ & $\sigma_{\mathrm{s}}$ & $\mathrm{f}_{\mathrm{fu}}^{*}$ & $\mathrm{E}_{\mathrm{f}}=\mathrm{E}_{\mathrm{f}, \mathrm{ave}}$ & $\varepsilon_{\mathrm{u}, \mathrm{ave}}$ & $\sigma$ & $\varepsilon_{\mathrm{fu}}^{*}$ \\
\hline BFRP & 1180.0 & 14.3 & 1137.1 & 47.6 & $2.6 \%$ & 0.20 & $2.0 \%$ \\
\hline HFRP & 1190.0 & 15.4 & 1143.8 & 64.3 & $2.2 \%$ & 0.02 & $2.1 \%$ \\
\hline
\end{tabular}

Despite the addition of carbon fibers, the mean tensile strength of HFRP bars did not increase, while the modulus of elasticity increased by as much as $35 \%$ compared to BFRP bars.

\section{Experimental programme}

\subsection{Model beams' preparation}

The tests were carried out on model beams with dimensions of $80 \times 120 \times 1100 \mathrm{~mm}$ made of C30/37 concrete with $w / c=0,50$. The cement CEM I $42.5 \mathrm{R}$ content was $320 \mathrm{~kg} / \mathrm{m}^{3}$. A mixture of sand and gravel with grain diameter up to $16 \mathrm{~mm}$ was used as aggregate. The concrete was composed taking into account the requirements for structural members intended for use in the exposure class XA2 (chemically aggressive environment) and XF3 (cyclic freezing and thawing) according to EN 206-1 [8].

Specification of beam specimens tested was given in Table 2. Every series consisted 3 replicates.

Table 2. Specification of model beams tested.

\begin{tabular}{|c|c|}
\hline $\begin{array}{c}\text { Series } \\
\text { designation }\end{array}$ & Description \\
\hline HFRP & beams reinforced with HFRP bars, subjected to short-term load \\
\hline BFRP & beams reinforced with BFRP bars, subjected to short-term load \\
\hline HFRP F & $\begin{array}{c}\text { beams reinforced with HFRP bars, subjected to static load and cyclic freezing and } \\
\text { thawing }\end{array}$ \\
\hline BFRP F & $\begin{array}{c}\text { beams reinforced with BFRP bars, subjected to static load and cyclic freezing and } \\
\text { thawing }\end{array}$ \\
\hline HFRP C & reference beams reinforced with HFRP bars, subjected to long-term static load \\
\hline BFRP C & reference beams reinforced with BFRP bars, subjected to long-term static load \\
\hline
\end{tabular}

The reinforcement system of the test elementswasbased on four main FRP bars with a diameter of $6 \mathrm{~mm}$ in each of the corners of the cross-section and steel stirrups with a diameter of $\varnothing 3 \mathrm{~mm}$ evenly spaced every $50 \mathrm{~mm}$. The test elements have been designed in accordance with the guidelines of ACI 440: 1R-06 [1], assumingthe crushing of the compression zone of concrete as destruction mechanism. 


\subsection{Test method}

In order to evaluate the failure mode of concrete beam with composite reinforcement and to determine the maximum failure load, the bending tests were performed after 28 days of curing. The midspan deflections under immediate load were monitored.

The assumptions of the long-term test were based on a comparison of the behavior of beams subjected to static load in three point bending test and at the same time to cyclic freezing and thawing at the temperature range from $-20^{\circ} \mathrm{Cto}+20^{\circ} \mathrm{C}$. In addition, reference beams loaded in the same way, were tested at a constant temperature of $20 \pm 2^{\circ} \mathrm{C}$. The midspan deflections of beams, strains of concrete at the levelof reinforcement as well as the spacing and widths of cracks were measured.

For simulating the conditions during the ordinary test procedure of frost resistance of concrete and limiting the drying of beams surface, all samples were pre-soaked with water and then they were tightly wrapped with plastic cover and the water losses were supplemented periodically during the test.

Specially designed test stands with model beams were placed in a freezing chamber, in which temperature regime was simulated. The 200 cycles were accepted as the period of test, with each freeze/thaw cycle lasting 8 hours.

Inverted static scheme (beam bending upwards) allows full exposure of the tensile edges of tested members, and thus current registration of crack morphology. The view of testing equipment in the freezing chamber was shown in Fig. 1.

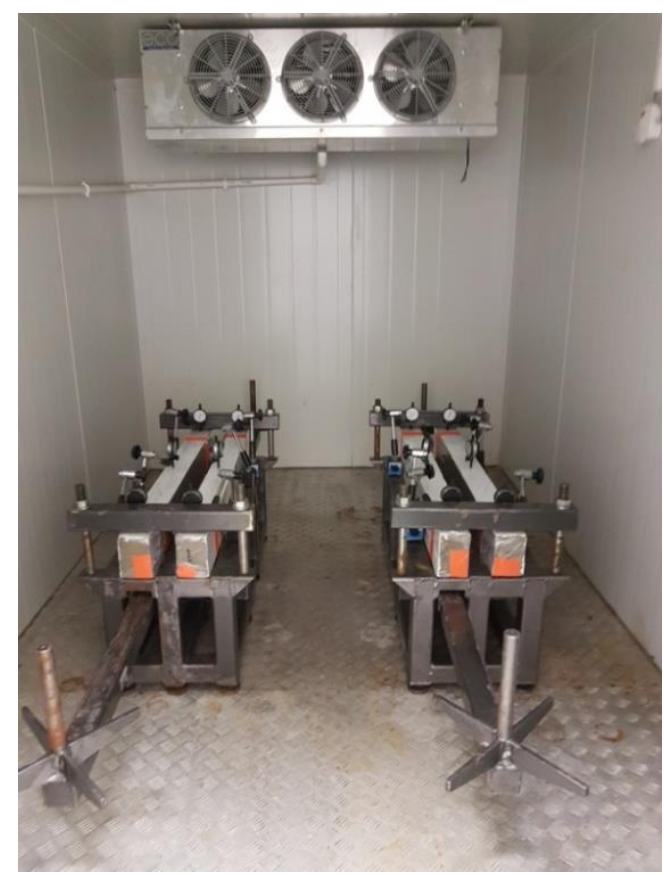

Fig. 1. Testing equipment in freezing chamber.

The value of the static load in the midspan of beam was established as the equivalent of $20 \%$ of the beam bearing capacity determined when testing the elements under the short term load. The assumed level of the test members effort corresponded to their reaching the ultimate limit state of deflection. Thus, the beams reinforced with BFRP and HFRP bars were loaded with different values of forces, which were equal to $5.60 \mathrm{kN}$ and $7.00 \mathrm{kN}$, respectively. 
The deflections were controlled using the moisture resistant dial gauges, with an accuracy of $0.01 \mathrm{~mm}$. The strains were measuredthrough benchmarks previously fixed on beams' surface. The contactless device with an accuracy of $0.001 \mathrm{~mm}$ with a measuring base of 150 $\mathrm{mm}$ was used for strains determination.

\section{Analysis and discussion of test results}

\subsection{Results of short-term test}

The results of monitoring the deflections of beams under short-term load are shown in Fig. 2.

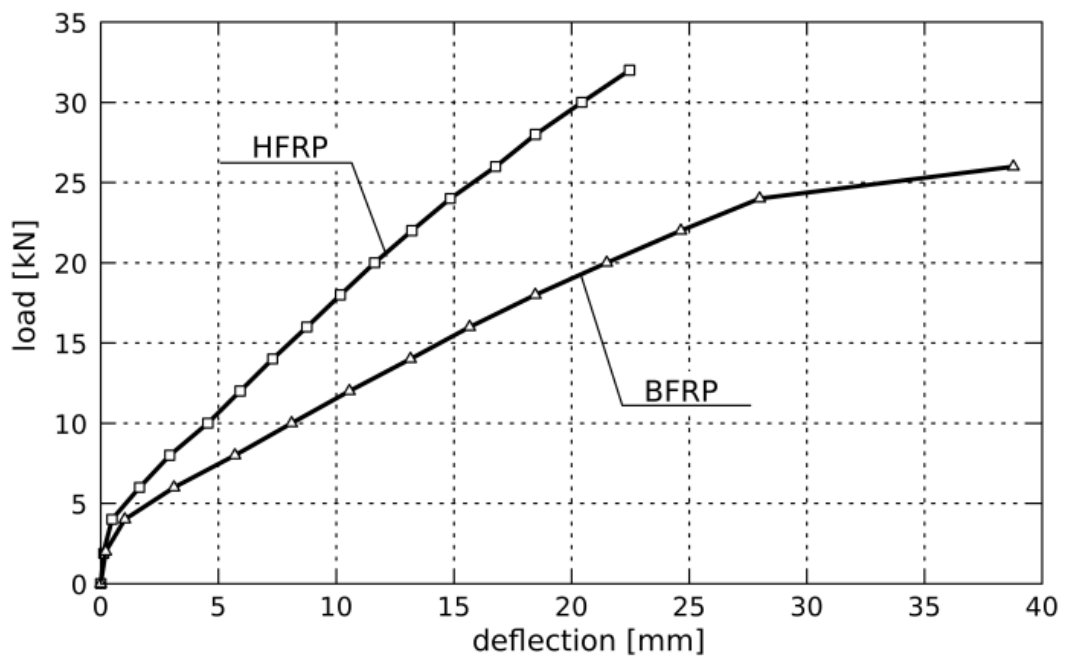

Fig. 2. Mean values of deflections of model beams with composite reinforcement.

Due to the small elastic modulus of composite reinforcement in comparison to the typical reinforcing steel, the beams with both type of bars showed significant deflections. The deflection increase was almost linear throughout the entire load range. The mean values of failure load was equal to $28 \mathrm{kN}$ and $34 \mathrm{kN}$, respectively for model beams with BFRP and HFRP bars.

Failure mode of the beam reinforced with HFRP bars was presented in Fig. 3. The failure due to combined effect of bending and shearing was observed in accordance with design assumptions. Shear zone was cracked but with no signs of damage. Rapid destruction in the tensile zone with crushing of concrete in the compression zone, deformation of compressed bars, breaking stirrups within the cracks and exposure of tensile reinforcement were observed. The tensile FRP bars in concrete work in similar way to steel reinforcement. The bond of concrete to the composite bars was kept throughout the entire load range. This was confirmed by the development of cracks - in the zone of reinforcement influence (in the bottom part of beam cross-section) cracks clearly branch out, and they connect into the form of cumulative crack above this zone. 


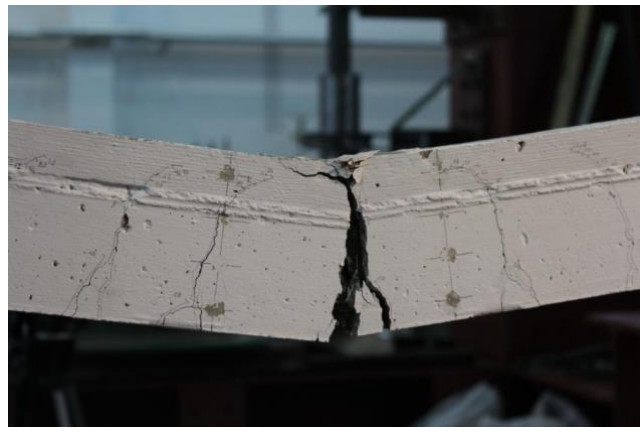

Fig. 3. Failure of beam due to concrete crushing.

\subsection{Results of long-term test}

The relationships of beam deflection versus number of freeze/thaw cycles in comparison to the results obtained for reference beam specimens tested under static load at the temperature of $20 \pm 2{ }^{\circ} \mathrm{C}$ were presented in Fig. 4 . The mean strains in tensile zone of concrete beams were presented in Fig. 5.

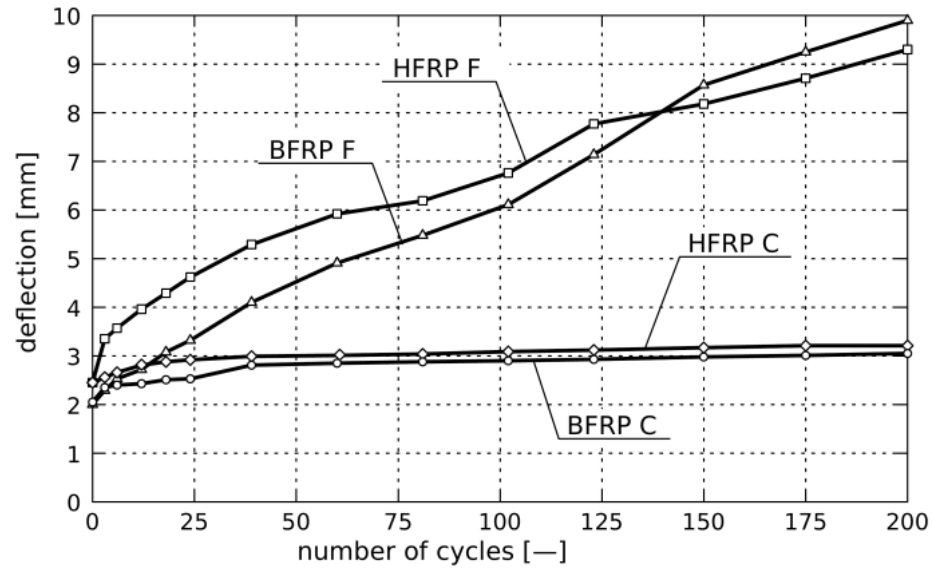

Fig. 4. Average values of midspan deflection of beams with composite reinforcement vs. number of freeze/thaw cycles.

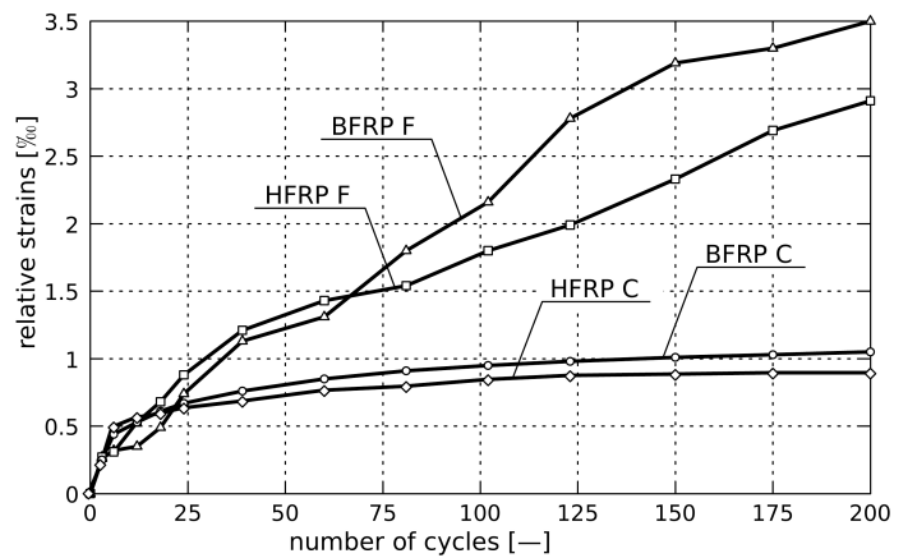

Fig. 5. Relative strains in tensile zone of beams vs. number of freeze/thaw cycles. 
When analyzing the absolute values of deflections (Fig. 4), it is necessary to consider the difference in the load values of beams with various types of composite reinforcement. At a considered load level, the deflection of beams tested at a constant temperature increased slightly in relation to the initial value obtained immediately after applying the load. However, the deflection of beams subjected to freeze/thaw cycles increased with almost constant rate, reaching a value more than three times higher than the deflection under an immediate load. After 200 cycles the mean values of deflections of beams with different types of composite reinforcement were comparable, although the absolute values of the load for both types of beams were different. The significant influence of cyclic freezing and thawing on beam deformations has also been confirmed by the analysis of strains in tensile zone. In the case of HFRP C and BFRP C beams subjected to load at a constant temperature, after initial slight increase, the deformations increased very slowly. The increase in strains in beams under freeze/thaw cycles (BFRP F and HFRP F) was almost linear throughout the test period and the values recorded were even three times greater in comparison to the strains in beams testedat constant temperature.

It can beseen in Fig 4 that for the beams tested at a constant temperature, the stabilization of the deflection increase took place after 40 freeze/thaw cycles. In contrast, for elements subjected to variable temperature conditions, the value of mentioned parameter was constantly increasing with the number of freeze/thaw cycles. In the final phase of the test, specimens subjected to freeze/thaw cycles, reinforced with BFRP and HFRP bars, achieved respectively $34 \%$ and $29 \%$ higher values of the total crack width in comparison to reference specimens BFRP C and HFRP C.

\section{Conclusion}

The long-term durability of FRP reinforced concrete structures can be very attractive in aggressive environments andthe BFRP and HFRP bars can be effectively used as reinforcement of concrete beams. However, achieving a beneficial effect of BFRP reinforcement on the bearing capacity and deformability of beam is conditioned by consideration of specific limitations and modifications related totheir mechanical parameters in the design process. The insertion of additional rovings of coal fiber around the original basalt fiber bars significantly improved the mechanical properties of the reinforcing bars, particularly their modulus of elasticity. It also had a beneficial effect on deformation characteristics of beams subjected to cyclic freezing and thawing.

The composites represent a promising alternative to traditional construction materials and techniques for a sustainable and durable infrastructure. The results obtained herein contribute to developing and enhancing the properties of BFRP and HFRP bars in concrete elements. Further investigations should be conducted to generate more confidence and encourage wider acceptance of this material, which may lead to introducing the BFRP bars into design codes and standards.

\section{Acknowledgement}

This research work was financially supported by National Centre for Research and Development, Poland; project number PBS3/A2/20/2015 (ID 245084).

\section{References}

1. ACI 440.1R-06, Guide for the design and construction of concrete reinforced with FRP bars., ACI Committee 440 (American Concrete Institute, USA, 2006) 
2. ACI 440.3R-04, Guide test methods for fiber-reinforced polymers (FRPs) for reinforcing or strengthening concrete structures, ACI Committee 440 (American Concrete Institute, USA, 2004)

3. S.E. Artemenko, Fiber Chemistry 35(3), 226 (2003)

4. P. Banibayat, A. Patnaik, Materials and Design 56, 898 (2014)

5. L.C. Bank, Composites for Construction: Structural design with FRP materials (John Willey and Sons LTD, 2006)

6. J. Branston, S. Das, S. Kenno, C. Taylor, Construction and Building Materials 124, 878 (2016)

7. F. Elgabbas, E. Ahmed, B. Benmokrane, Construction and Building Materials 95, 623 (2015)

8. EN 206+A1:2016-12, Concrete - Specification, performance, productionand conformity (2017)

9. V. Fiore, G. Di Bella, A. Valenza, Material Design 32, 2091 (2011)

10. M. Inmana, M. R. Thorhallssonb, K. Azraguea, Energy Procedia 111, 31 (2017)

11. C. High, H.M. Seliem, A. El-Safty, S.H. Rizkalla, Construction and Building Materials 96, 37 (2015)

12. N. Kabay, Construction and Building Materials 50, 95 (2014)

13. A.K.H. Kwan, C.X. Dong, J.C.M. Ho, Engineering Structures 99, 285 (2015)

14. G. Li, J. Wu, W. Ge, Construction and Building Materials 93, 1059 (2015)

15. A. Mosallam, H.M. Elsanadedy, T.H. Almusallam, Y.A. Al-Salloum, S.H. Alsayed, Composite Structures 124, 421 (2015)

16. D. Mostofinejad, M. Mohammadi Anaei, Engineering Structures 41, 1 (2012)

17. E.P. Najafabadi, M. Bazil, H. Ashrafi, A.V. Oskouei, Construction and Building Materials 171, 960 (2018)

18. R. Sene, G. Mullins, Composite Part B: Engineering 38, 571 (2007)

19. J. Sim, C. Park, D. Moon, Composites Part B: Engineering 36, 504 (2005)

20. M. Urbański, A. Łapko, A. Garbacz, Procedia Engineering 57, 1183 (2013)

21. K. Van de Velde, P. Kiekens, L. Van Langenhove, S. Cater, Editorial, International Composites News, Basalt fibers as reinforcement for composites March (2002)

22. H. Wang, X. Sun, G. Peng, Y. Luo, Q. Ying, Construction and Building Materials 95, 448 (2015)

23. X. Wang, Z. Wang, Z. Wu, F. Cheng, Construction and Building Materials 73, 781 (2014)

24. B. Wei, H.Cao, S.Song, Materials Science and Engineering A 527, 4708 (2010)

25. O. Youssf, M. A. El Gawady, J.E. Mills, Engineering Structures 101, 465 (2015)

26. H. Zhang, S. Chen, Y.B. Zhao, M.W. Li, Railway Standard Design 3(24), 73 (2011) 